\title{
APLICATIVO SECRET: SOMOS TODOS INVISÍVEIS? UM OLHAR CONSTITUCIONAL SOBRE O DIÁLOGO ENTRE ANONIMATO E LIBERDADE DE EXPRESSÃO NO AMBIENTE VIRTUAL
}

\section{APPLICATIVE SECRET: ARE WE ALL INVISIBLES? A CONSTITUCIONAL VIEW BETWEEN ANONIMITY AND FREEDOM OF SPEECH IN VIRTUAL ENVIRONMENT}

\begin{abstract}
BÁRBARA Michele MORAIS KUNDE
Mestre em Direitos Sociais e Políticas Públicas pela Universidade de Santa Cruz do Sul - Unisc, com Bolsa Capes. Especialista em Direito Ambiental pela Universidade Luterana do Brasil - Ulbra. Graduada em Direito pela Universidade do Vale do Rio do Sinos - Unisinos. Advogada. Professora na Graduação da Universidade de Santa Cruz do Sul - Unisc. barbarakunde@gmail.com

JORGE RENATO DOS REIS Pós-Doutor pela Università Degli Studi di Salerno-Itália com bolsa CAPES. Doutor pela Universidade do Vale do Rio dos Sinos-UNISINOS. Mestre em Desenvolvimento Regional pela Universidade de Santa Cruz do Sul-UNISC. Especialista em Direito Privado pela Universidade de Santa Cruz do Sul-UNISC. Graduado em Direito pelas Faculdades Integradas de Santa Cruz do Sul-FISC. Professor e pesquisador do Programa de Pós-Graduação Stricto-Sensu-Mestrado e Doutorado em Direito da UNISC.jreis@unisc.br
\end{abstract}

\section{RESUMO}

A Constituição Federal brasileira, vértice do ordenamento jurídico, tutela a liberdade de expressão em grande amplitude, vedando, no entanto, o anonimato. Considerando-se a existência de um aplicativo para celulares denominado Secret, que assegura a postagem de mensagens, no mundo virtual, de forma anônima, e tendo em vista o atual modelo democrático que prima pela liberdade de expressão com responsabilidade, não é possível que o emissor da informação não seja identificado, sob pena de eventualmente, no exercício de sua expressão, em caso de abuso, violar o direito de personalidade alheio. Por outro lado, se permitido o uso do referido aplicativo, até que ponto ele fomenta o discurso do ódio? Considerando-se a comunicação instantânea e global, percebe-se que o potencial lesivo é bastante acentuado, reclamando, portanto, uma proteção ainda mais intensa pelo Direito, convocando o Órgão das Nações Unidas a adotar medidas neste sentido. 0 que se deve perseguir é realização plena da dignidade da pessoa humana, valor universal, e princípio basilar dos sistemas jurídicos.

Palavras-chave: Ambiente virtual; anonimato; discurso do ódio; liberdade de expressão; responsabilidade.

\begin{abstract}
The Brazilian Federal Constitution, apex of the legal system, protects the freedom of expression in large amplitude, sealing, however, anonymity. Considering the existence of a mobile application called Secret, which ensures the posting, in the virtual world, anonymously, and in view of the current democratic model that stands for freedom of expression responsibly, it is not possible for the information sender is not identified, otherwise possibly in the exercise of its expression, in case of abuse, violating someone else's personality rights. On the other hand, if allowed the use of said application, to what extent it promotes hate speech? Considering the instantaneous and global communication, it is clear that the harmful potential is quite sharp, complaining, so an even more intense protection by the law, calling the UN Agency to take steps in this direction. What should pursue is the full realization of human dignity, universal value and basic principle of legal systems.
\end{abstract}

Keywords: Virtual environment; anonymity; hate speech; freedom of speech; responsibility. 
APLICATIVO SECRET: SOMOS TODOS INVISÍVEIS? UM OLHAR CONSTITUCIONAL SOBRE O DIÁLOGO ENTRE ANONIMATO E LIBERDADE DE EXPRESSÃO NO AMBIENTE VIRTUAL

Bárbara Michele MORaIS Kunde, Jorge Renato dos ReIS

\section{SUMÁRIO}

INTRODUÇÃO; 2. A LIBERDADE DE EXPRESSÃO NO ATUAL MODELO DEMOCRÁTICO E A VEDAÇÃO DO ANONIMATO 3. O APLICATIVO SECRET COMO FERRAMENTA DE RELACIONAMENTO NO MUNDO VIRTUAL 4. O ANONIMATO E A (POSSÍVEL) PROBLEMÁTICA DO DISCURSO DO ÓDIO SOB A ÓTICA VIRTUAL 5. EM BUSCA DE UM EQUILÍBRIO: A TUTELA CONSTITUCIONAL DA LIBERDADE DE EXPRESSÃO E O AMBIENTE VIRTUAL 6. CONCLUSÃO 7. REFERÊNCIAS.

\section{INTRODUÇÃO}

A liberdade de expressão traduz-se como um dos pilares da democracia, ancorada no artigo $5^{\circ}$, inciso IV da Constituição Federal, foi consagrada como direito fundamental em resposta ao período repressor vivido pelo Brasil durante a ditadura militar.

Diante desse novo viés pluralista, a participação política passou a ser também uma das bases da democracia, de modo que o pensamento pode ser exteriorizado livremente, e, com base no princípio da dignidade da pessoa humana, todos os cidadãos passaram a ser agentes ativos na construção desta nova sociedade.

O presente artigo primeiramente contextualizará a tutela da liberdade de expressão no ordenamento jurídico brasileiro e a vedação ao anonimato, uma vez que a Constituição Federal prevê a responsabilidade do emissor da informação que viole direito alheio, notadamente quando se trata de ambiente virtual e suas avançadas e tecnológicas ferramentas comunicativas.

$\mathrm{Na}$ sequência se analisará o ambiente de comunicação virtual e a utilização específica do aplicativo para smartphones, iPads e iPhones denominado Secret, e seu impacto social nas relações humanas, inclusive em nível internacional. A comunicação massiva e interativa, aliada ao anonimato, assegurado às mensagens veiculadas por meio do referido aplicativo, pode abrir vasto campo ao discurso do ódio, desvirtuando, assim, a liberdade de expressão. Nesse sentido, a dignidade da pessoa humana sempre deve pautar qualquer exercício de direito, e por isso o anonimato evidenciado pelo aplicativo não merece tutela, pois não tem guarida constitucional.

Nesse contexto, a independência de consciência do ser humano é necessária para o seu pleno desenvolvimento, cuja dignidade somente será assegurada quando tiver ele a possiblidade de se autodeterminar. Quando o indivíduo é senhor de suas escolhas, naturalmente dá a sua contribuição na construção de uma sociedade mais justa e solidária, caminhando na direção oposta da intolerância e do discurso do ódio, como veremos. 
APLICATIVO SECRET: SOMOS TODOS INVISÍVEIS? UM OLHAR CONSTITUCIONAL SOBRE O DIÁLOGO ENTRE ANONIMATO E LIBERDADE DE EXPRESSÃO NO AMBIENTE VIRTUAL

BÁRbara Michele Morais Kunde, JoRge Renato dos ReIS

Considerando-se a existência desse aplicativo para celulares, que assegura a postagem de mensagens, no mundo virtual, de forma anônima, e tendo em vista o atual modelo democrático que prima pela liberdade de expressão, o primeiro problema enfrentado é se a proibição de utilização do referido aplicativo viola este direito, centrando-se no ordenamento jurídico brasileiro, mas também mencionando, ainda que brevemente, o cenário internacional. Em um segundo enfrentamento, problematiza-se se se uma vez permitido o aplicativo, o anonimato fomenta o discurso do ódio pela impossibilidade de identificação do autor da postagem. Para tanto se empregou o método hipotético-dedutivo utilizando-se uma decisão do Poder Judiciário do estado do Espírito Santo, e como técnica de pesquisa a bibliográfica, recolhendo elementos em livros e periódicos para a definição e dimensionamento do direito fundamental à liberdade de expressão e a vedação do anonimato, bem como do discurso do ódio no ordenamento jurídico brasileiro. A pesquisa forneceu elementos para a solução do problema proposto, concluindo que, neste caso concreto, o anonimato albergado pelo referido aplicativo viola a Constituição brasileira, uma vez que estimula a intolerância e o discurso do ódio pela ideia de liberdade plena, minando, portanto, a dignidade da pessoa humana.

\section{A liberdade de expressão no atual modelo democrático e a vedação do anonimato}

Intensa repressão a quaisquer movimentos político-sociais foi a grande característica do regime ditatorial vivido pelo Estado brasileiro por décadas. Anos de imposição de silêncio e atos de violações cruéis aos direitos humanos levaram a prisões arbitrárias, utilização de métodos de interrogatórios torturantes, censura de quaisquer manifestações, culminando, não raras vezes, no desaparecimento de pessoas consideradas subversivas ao sistema.

Porém, como os movimentos sociais não passaram ao largo da história brasileira, nos anos de 1980 deflagrou-se o processo de abertura democrática, resultando, ao final da década, na promulgação da Constituição Cidadã. Nesse passo, avançou-se ao Estado Democrático de Direito, fundado em princípios de cidadania, soberania, pluralismo político, solidariedade e justiça, iniciando-se, assim, um período de exercício da liberdade em suas várias facetas.

A fim de compatibilizar o interesse constitucional de promoção de uma sociedade democrática, o Estado abandona sua posição superior abrindo espaço político para a participação 
APLICATIVO SECRET: SOMOS TODOS INVISÍVEIS? UM OLHAR CONSTITUCIONAL SOBRE O DIÁLOGO ENTRE ANONIMATO E LIBERDADE DE EXPRESSÃO NO AMBIENTE VIRTUAL

Bárbara Michele Morais Kunde, JoRge Renato dos ReIS

popular, trilhando-se o caminho da concretização dos direitos e garantias fundamentais já reconhecidos formalmente.

Como corolário desta nova ordem político-social, a participação se deu pela liberdade de expressão, antecedida pela liberdade de pensamento, condição intrínseca de todo ser humano, campo mental onde concebe seus valores e crenças.

Por desempenhar tão relevante papel na legitimação dos regimes democráticos, a liberdade de expressão é um dos mais caros e estimados direitos do cidadão. E, segundo discorre Edilsom Pereira de Farias", atualmente é entendida como "um direito subjetivo fundamental assegurado a todo cidadão, consistindo na faculdade de manifestar livremente o próprio pensamento, ideias, opiniões através da palavra, escrito, imagem ou qualquer outro meio de difusão".

Este universo informacional disponibiliza ao cidadão a liberdade de concordar ou discordar das informações a que tem acesso, oportunizando-lhe, neste panorama, defender seu ponto de vista, consolidando, assim, a sua identidade perante o grupo social.

Logo, vige em nossa ordem jurídica o direito fundamental de liberdade de expressão pluralista. Porém, caso haja alguma violação, a Constituição assegura o direito de ressarcimento contra quem perpetrou a lesão. Quando a informação é lançada no ambiente virtual sem possibilidade de identificação de seu emissor, e seu conteúdo é ofensivo, não há um sujeito que possa ser responsabilizado, daí o anonimato ser vedado. Do contrário, estar-se-ia "dando com uma mão e tirando com a outra”, ou seja, a liberdade de expressão deve ser responsável, sob pena de indenização.

Nesse sentido, o anonimato caracteriza-se pela identidade oculta, protegendo, de certo modo, o emissor da ideia. Esta invisibilidade pode estimular a propagação de informações, nem sempre verídicas, de uma forma leviana, irresponsável e violenta.

O anonimato já não era permitido desde a Constituição republicana brasileira de 1891. Originariamente concebida no contexto de publicação de livros, panfletos e jornais, instituía a liberdade de tribuna independente de censura, e já previa a responsabilização pelos abusos cometidos. 0 século $\mathrm{XX}$, marcado por lutas políticas, transformou a imprensa (canal mais dinâmico da liberdade de expressão), dando-lhe uma tônica essencialmente capitalista,

\footnotetext{
${ }^{1}$ FARIAS, Edilsom Pereira. Colisão de direitos - A honra, a intimidade, a vida privada e a imagem versus a liberdade de expressão e informação. 3.ed. rev. e atual. Porto Alegre: Fabris, 2008, p. 145.
} 
APLICATIVO SECRET: SOMOS TODOS INVISÍVEIS? UM OLHAR CONSTITUCIONAL SOBRE O DIÁLOGO ENTRE ANONIMATO E LIBERDADE DE EXPRESSÃO NO AMBIENTE VIRTUAL

Bárbara Michele Morais Kunde, JoRge Renato dos ReIS

fomentando a discussão no âmbito privado. Com a ascensão dos militares ao poder, a censura passou a ser regra até a democratização do estado brasileiro, quando então as discussões passaram também à natureza político-social ${ }^{2}$.

Com a Constituição Federal de 1988 a proibição do anonimato, consagrada no inciso IV do artigo $5^{\circ}$, estendeu-se aos meios de comunicação e, com a inovação tecnológica, alcançou os meios virtuais, com o escopo de garantir também a privacidade, a honra e o sigilo dos indivíduos.

Nesse sentido, o processo comunicativo, expressão aqui empregada de forma geral para designar os processos de expressar-se, assume papel de grande relevo nas relações sociais, pois o ambiente virtual proporciona acesso amplo e global a milhares de pessoas, conectadas aos mesmos canais.

Ressalte-se, ainda, que a liberdade de expressão, por ser um dos pilares do regime democrático, se assenta em bases de responsabilidade, isto é, além de se revelar um direito individual, é também contaminado pelo senso coletivo em virtude das transformações dos meios de comunicação ${ }^{3}$.

Dentre este amplo leque de ferramentas comunicativas que possibilitam a concreção da liberdade de expressão no atual Estado contemporâneo, importante realçar que as relações humanas também se constroem sobre estas mesmas bases tecnológicas, interligando os indivíduos através de diferentes caminhos, dentre os quais interessa ao presente estudo mais especificadamente aquelas pertinentes ao ambiente virtual, como em seguida se verá.

Por esse motivo é que a discussão sobre a possibilidade de utilização do aplicativo Secret é plenamente cabível, pois não importa o quão avançadas são as tecnologias, estas devem ser utilizadas para promover a dignidade da pessoa humana, suscitando o bem-estar individual e contribuindo para o desenvolvimento coletivo. O objetivo, pois, é alcançar uma convivência harmônica, solidificada em valores ético-morais voltados à justiça social.

\section{0 aplicativo Secret como ferramenta de relacionamento no ambiente}

\section{virtual}

\footnotetext{
${ }^{2}$ SODRÉ, Nelson Werneck. História da imprensa no Brasil. 4 ed. atual. Rio de Janeiro: Mauad, 1999.

${ }^{3}$ SILVA, José Afonso da. Comentário contextual à Constituição. São Paulo: Malheiros, 2005, p. 252.
} 
APLICATIVO SECRET: SOMOS TODOS INVISÍVEIS? UM OLHAR CONSTITUCIONAL SOBRE O DIÁLOGO ENTRE ANONIMATO E LIBERDADE DE EXPRESSÃO NO AMBIENTE VIRTUAL

Bárbara Michele Morais Kunde, JoRge Renato dos ReIS

O ambiente virtual criou um novo espaço e novos modos de conversação, tornou possível a transmissão e recebimento de informações por meio de aplicativos de comunicação instantânea, cada vez mais populares e acessíveis, tornando-os um dos principais caminhos para exercer a liberdade de expressão.

Computadores e smartphones, além de serem máquinas dotadas de tecnologia de última geração que permitem uma interação entre muitos indivíduos interligados nas redes, são instrumentos que fazem com que a transmissão da informação ocorra de forma vertiginosamente veloz e com abrangência global. Nesse contexto, não raro as manifestações de pensamento extrapolam o âmbito restrito da privacidade, geralmente com uma dimensão não delimitada, causando, seu conteúdo, um grande impacto social, interferindo decisivamente na qualidade de vida dos cidadãos. Em âmbito internacional, a diferença está no tratamento que é dispensado à proteção da privacidade pelos diferentes países, uma vez que o mundo virtual, sem fronteiras, alcança lugares inimagináveis.

O aplicativo Secret foi desenvolvido, nos Estados Unidos pela Apple e pela Google, para uso em smartphones. Livre de qualquer custo conquistou um grande público, principalmente de crianças e adolescentes, atraídas pelo fato de contar segredos de seus contatos do Facebook nas redes sociais. 0 diferencial atrativo desta ferramenta foi a divulgação de fotos e comentários de forma anônima e livre, que, uma vez compartilhados, permitiam a outros usuários acrescer seus próprios comentários ${ }^{4}$.

Não se pode deixar de mencionar que o referido aplicativo, criado para usuários nos Estados Unidos, foi concebido sob um regime do free speech, em que a liberdade de expressão é hoje certamente o direito fundamental mais valorizado, tendo peso preferencial quando ponderada com outros direitos fundamentais ${ }^{5}$. Desse modo, a tradição libertária tem quase

\footnotetext{
${ }^{4}$ Artigo de autoria de Paulo Roberto Narezi. Disponível em: <http://www.gazetadopovo.com.br/vidapublica/justica-direito/artigos/aplicativo-secret-entre-a-liberdade-de-expressao-e-a-vedacao-aoanonimato-ecozwkk80utuljlu4x6b6iyxa> Acesso: em 20 maio 2015.

5 Vale destacar a relevante observação de Daniel Sarmento, em seu artigo "Liberdade de expressão, pluralismo e papel promocional do Estado: "Embora a jurisprudência norte-americana tenha afirmado, desde o julgamento do caso Griswold vs. Connecticut, ocorrido em 1965, a existência de um direito fundamental implícito à privacidade, situado nas "zonas de penumbra" do Bill of Rights, e expandido corajosamente as fronteiras deste direito para abarcar até a liberdade da mulher de praticar o aborto (Roe vs. Wade), ela tende a atribuir um peso muito superior à liberdade de expressão em casos de colisões. Para ilustrar esta afirmação, basta mencionar que, segundo a jurisprudência da Suprema Corte, a imprensa tem o direito de divulgar o nome de vítimas de estupro (Landmark Communications Inc. vs. Virginia - 435 U.S. 829 (1978)) e de expor ao público o conteúdo de conversas telefônicas de particulares gravadas ilicitamente, sem autorização judicial (Bartnicki vs. Vopper - 121 S. Ct. 1753 (2001))."
} 
APLICATIVO SECRET: SOMOS TODOS INVISÍVEIS? UM OLHAR CONSTITUCIONAL SOBRE O DIÁLOGO ENTRE ANONIMATO E LIBERDADE DE EXPRESSÃO NO AMBIENTE VIRTUAL

Bárbara Michele Morais Kunde, JoRge Renato dos ReIS

sempre prevalecido na trajetória histórica da $1^{\text {a }}$ Emenda, e é ela que hoje impera no Direito Constitucional norte-americano.

A ferramenta tecnológica norte-americana baseou-se na Câmara Arbitral da Califórnia, trazendo uma breve ressalva acerca dos usuários internacionais, alertando sua regulamentação pela lei americana, e, por consequência, a automática aceitação de seus termos de uso, que equivalem a contratos de adesão.

Nesse contexto, como já mencionado, de liberdade ampla e quase irrestrita, os termos da política de uso do referido aplicativo estimulava o anonimato, alertando para a possibilidade de contestação de eventual pedido de identificação do usuário por meio da Primeira Emenda à Constituição norte-americana, disponibilizando, inclusive, uma ferramenta que permitia desvincular a postagem do usuário à sua identidade.

Evidentemente que o aplicativo não se adequou à legislação brasileira, gerando uma série de consequências jurídicas. A complexidade e relevância do tema, no entanto, merecem pesquisa aprofundada, de forma que o presente estudo se concentrará na vedação do anonimato e suas consequências quanto à vivência da intolerância e, em casos extremos, da prática do discurso do ódio.

O Secret tornou-se ainda mais sedutor pela ampla sensação de liberdade proporcionada pelo desconhecimento da identidade de seus usuários. Evidentemente que esta liberdade irresponsável redundaria em abusos, já que o ambiente virtual é bastante eficaz na disseminação de informações, seja pelo amplo alcance, seja pela velocidade com que circulam as notícias.

Analisando a casuística do caso concreto, verifica-se que se tratou de publicação de fotos íntimas envolvendo um rapaz de 25 anos, sobre as quais houve diversos comentários afirmando ser ele portador do vírus HIV, contraído em orgias sexuais com seus amigos. Como prometido pelo referido aplicativo, os comentários foram totalmente apócrifos e não sofreram qualquer moderação quanto ao conteúdo.

Por esse motivo, a notícia ensejou o ajuizamento de uma ação civil pública pelo Ministério Público Federal na comarca de Vitória ${ }^{6}$, na qual foi requerida a suspensão do download do aplicativo e sua remoção imediata das lojas da Apple, Microsoft e também do sítio

\footnotetext{
${ }^{6}$ BRASIL. Tribunal de Justiça do Espírito Santo. Acórdão de decisão que concedeu efeito suspensivo ao agravo de instrumento. Agravo de Instrumento $\mathrm{n}^{\circ}$ 0035186-28.2014.8.08.0024. Ministério Público do Espírito Santo e Apple Computer Brasil Ltda., Google Brasil Ltda., e Microsoft Informática Ltda. Relator: Desembargador Robson Luiz Albanez. 06 de novembro de 2014. Disponível em: <http://aplicativos.tjes.jus.br/sistemaspublicos/consulta_12_instancias/descricao_proces.cfm> Acesso em: 24 maio 2015. BRASIL.
} 
APLICATIVO SECRET: SOMOS TODOS INVISÍVEIS? UM OLHAR CONSTITUCIONAL SOBRE O DIÁLOGO ENTRE ANONIMATO E LIBERDADE DE EXPRESSÃO NO AMBIENTE VIRTUAL

Bárbara Michele Morais Kunde, JoRge Renato dos ReIS

eletrônico do Google, sob o argumento de violação da intimidade e da honra, já que a liberdade de expressão no Brasil além de não ser absoluta, é restringida pela proibição ao anonimato.

0 pedido foi deferido liminarmente, no entanto, em segundo grau, a medida foi revogada sob a justificativa de que efetivamente não havia o anonimato, pois os provedores deveriam manter dados passíveis de identificar os internautas. A decisão referiu, ainda, que o anonimato não é exclusivo deste aplicativo, sendo assegurado em outros tantos e até mesmo em sites e redes sociais.

Diante de toda a polêmica, mesmo tendo sua disponibilização liberada, o aplicativo teve suas atividades encerradas por seu idealizador, em abril de 2015, justificando que a ferramenta não representava mais a visão que possuía quando de sua criação, que era de assegurar uma expressão aberta e expressão criativa ${ }^{7}$.

Todavia, ainda que o aplicativo Secret tenha sido indisponibilizado, a discussão acerca da limitação à liberdade de expressão permanece, pois certamente outras ferramentas comunicativas virtuais surgirão para atender aos desejos dos consumidores, e poderão redundar em violação aos direitos fundamentais.

Além disso, partindo-se do fato de que a grande aceitação e adesão ao Secret ocorreu entre adolescentes e crianças, o estímulo ao anonimato pode gerar consequências nefastas, trazendo inarredáveis prejuízos à formação da personalidade destes indivíduos, seja como autores, seja como vítimas, pois estes conteúdos inapropriados podem ser eleitos como verdades absolutas em razão da sua pouca maturidade psicológica.

Nessa nova vertente de pensamento, interessa ao Direito tema tão relevante, uma vez que um dos pilares da democracia é a liberdade de expressão, que assegura a livre circulação de opiniões pelos meios tecnológicos existentes. Em resumo bastante raso, evoluindo-se as ferramentas da comunicação, o direito fundamental de expressar opiniões, ideias, emoções e pensamentos acompanha este progresso, levando consigo, necessariamente, a sua proteção, que não é mitigada em face das facilidades da sociedade da informação.

A sociedade da informação não é fruto de um país, ao contrário, é composta por meio da interação entre diferentes culturas, e por isso relevante retratar, ainda que brevemente, o cenário internacional acerca das novas tecnologias e o tratamento dispensado à privacidade.

\footnotetext{
${ }^{7}$ Notícia veiculada através do Portal G1, disponível em <http://g1.globo.com/tecnologia/tem-umaplicativo/noticia/2015/04/app-secret-de-posts-anonimos-chega-ao-fim-anuncia-criador.html $>$ Acesso em 15 jun 2015.
} 
APLICATIVO SECRET: SOMOS TODOS INVISÍVEIS? UM OLHAR CONSTITUCIONAL SOBRE O DIÁLOGO ENTRE ANONIMATO E LIBERDADE DE EXPRESSÃO NO AMBIENTE VIRTUAL

BÁRbara Michele Morais Kunde, Jorge Renato dos Reis

Importante resgatar que a liberdade de expressão é direito supremo nos Estados Unidos, tendo a preferência e preponderância nos julgamentos das Cortes, daí o estímulo ao anonimato ser algo natural.

Já o conceito deste direito fundamental no ordenamento alemão difere substancialmente do americano, atribuindo-se à liberdade de expressão uma dupla dimensão, que bem salienta Daniel Sarmento:

A ideia básica é a de que a liberdade de expressão desempenha um duplo papel: por um lado, ela constitui um direito subjetivo individual, vital para a dignidade humana, mas, por outro, ela é também um instrumento para a livre formação da opinião pública e para o intercâmbio de ideias entre os cidadãos, tão necessários ao funcionamento de um regime democrático. Esta primeira dimensão individual da liberdade da expressão tende a preponderar em casos envolvendo direitos de cidadãos comuns, artistas, escritores, etc., enquanto a segunda dimensão institucional e objetiva é mais enfatizada em questões relativas à imprensa em geral $^{8}$.

Relativamente às mídias eletrônicas, o autor destaca que a visão geral sobre os julgamentos levados a efeito no sistema germânico, é de que "a liberdade de expressão não é só um direito subjetivo a serviço do seu titular, mas também um valor, diretamente associado à democracia, que deve ser promovido ativamente pelo Estado"', o que significa dizer que há obrigação positiva de garantir o exercício deste direito, zelando pelo pluralismo na esfera comunicativa, assim como garantindo o seu exercício mesmo em face de ameaças perpetradas por particulares.

O Direito francês, de um modo geral, tende a priorizar a tutela de interesses como a ordem pública, o direito à honra e à privacidade quando conflitantes com a liberdade de expressão. Assim, a doutrina e a jurisprudência, diante da ausência de um critério uniforme pela lei, fizeram com que o direito à vida privada conquistasse praticamente a categoria de direito fundamental ${ }^{10}$.

A Lei italiana traz o direito à identidade como direito personalíssimo, considerando o sujeito sob a perspectiva de que é um ser único, irrepetível, titular de uma identidade social, que resguarda a sua posição no corpo social. Este direito, no entender de Têmis Limberger não

\footnotetext{
${ }^{8}$ SARMENTO, Daniel. Liberdade de expressão, pluralismo e o papel promocional do Estado. In: Revista Diálogo Jurídico, n. 16 - maio / junho / julho / agosto de 2007, Salvador, p. 12.

${ }^{9}$ Idem, p. 16.

${ }^{10}$ LIMBERGER, Têmis. 0 direito à intimidade na era da informática: a necessidade de proteção dos dados pessoais. Porto Alegre: Livraria do Advogado, 2007, p. 90.
} 
APLICATIVO SECRET: SOMOS TODOS INVISÍVEIS? UM OLHAR CONSTITUCIONAL SOBRE O DIÁLOGO ENTRE ANONIMATO E LIBERDADE DE EXPRESSÃO NO AMBIENTE VIRTUAL

Bárbara Michele Morais Kunde, JoRge Renato dos ReIS

implica deixar de fazer algo, mas sim, uma "possibilidade positiva de que alguém possa expressar a sua própria personalidade, com a pretensão de que possa ser percebida pelos demais". E como o direito à identidade é assegurado a todos os cidadãos, é possível limitar a liberdade de alguns ${ }^{11}$.

Em vista do exposto, percebe-se que o tratamento dispensado à liberdade de expressão e sua colisão com a privacidade é variável conforme o ordenamento jurídico, não há uma uniformidade, pois a trajetória histórica de cada qual justifica a prevalência de um ou outro direito.

Em que pese a tecnologia não encontre fronteiras nem limites, a legislação do país em que utilizada deve ser aplicável conforme a tutela prevalente dos seus interesses.

Por isso é que na Alemanha a liberdade de expressão é mormente defendida mesmo em face da privacidade do sujeito, tendo em vista a marca histórica de cerceamento de informações e manifestações de opiniões impostos pelo regime nazista. No mesmo norte, a lei italiana limita a liberdade de alguns para que o direito à identidade, levado a cabo pela liberdade de expressão, seja um fator de reconhecimento do indivíduo no corpo social em que inserido.

Em ângulo oposto, a França erigiu o direito à intimidade e à vida privada ao patamar de direito fundamental, restringindo, portanto, a ampla liberdade de expressão.

O Brasil, como é sabido, pondera a liberdade de expressão com o direito à privacidade no caso concreto, geralmente prevalecendo aquela em face desta, conforme inúmeros julgamentos realizados pelo Supremo Tribunal Federal.

A era digital fomenta esta diversidade, e por esse motivo também gerou preocupação por parte das Nações Unidas, acentuada a partir do vazamento de informações sobre espionagem internacional praticada por diversas agências de inteligência em 2013.

Reconhecendo a necessidade de assegurar proteção contra ingerências arbitrárias ou ilegais na vida privada dos homens, em julho de 2015 o Conselho de Direitos Humanos, em Genebra e com apoio de cinquenta e oito países, aprovou a nomeação de um relator especial acerca do direito à privacidade na era digital. Nos próximos três anos o relator deverá reunir informações sobre o direito à privacidade, bem como propor medidas para promovê-lo e protegê-lo, além de relatar situações de violação.

${ }^{11}$ Idem, p. 93-94. 
APLICATIVO SECRET: SOMOS TODOS INVISÍVEIS? UM OLHAR CONSTITUCIONAL SOBRE O DIÁLOGO ENTRE ANONIMATO E LIBERDADE DE EXPRESSÃO NO AMBIENTE VIRTUAL

Bárbara Michele Morais Kunde, JoRge Renato dos ReIS

$\mathrm{Na}$ ocasião a ONU reconheceu a importância das tecnologias da informação e comunicação, e reafirmou que os mesmos direitos que as pessoas têm em sua vida, devem ser também protegidos on line, incluindo o direito à privacidade.

Os resultados serão conhecidos em breve e poderão indicar, de modo mais seguro, as medidas protetivas a serem tomadas. Tal desiderato comprova a preocupação da afirmação dos direitos humanos também no ambiente virtual, buscando uma administração multilateral a ser observada pelos países signatários ${ }^{12}$.

Nesse norte, embora cada país confira proteção ora ao direito à privacidade, ora à liberdade de expressão no campo virtual, futura orientação da Nações Unidas virá em benefícios de todos os usuários, pois indicará as diretrizes a serem seguidas pelos aderentes ao relatório segundo o direito internacional dos direitos humanos.

Analisando-se o conteúdo do projeto já se pode ter uma ideia dos resultados que se buscam alcançar, pois no referido documento já se conclama os países a respeitar e proteger o direito à privacidade, inclusive no contexto das comunicações digitais, por meio da adoção de medidas com vistas à cessação das violações, além da revisão de procedimentos e práticas adotados, bem como a legislação, objetivando identificar e esclarecer princípios, padrões de conduta e melhores práticas de respeito aos direitos humanos.

Feitas estas considerações gerais em nível internacional, relevante direcionar o tratamento à liberdade de expressão no ordenamento jurídico brasileiro, cujas decisões apontam uma tendência de sobrepujar a privacidade e intimidade à liberdade de expressão. Entretanto a mitigação da privacidade deve vir acompanhada de um requisito fundamental e indispensável: a responsabilidade do emissor da opinião. Desse modo, no método da ponderação entre tais direitos fundamentais, o julgador acresce ao seu julgamento o comando constitucional de vedação ao anonimato.

Além disso, destaque-se que mesmo em face da era tecnológica, na qual inúmeras ferramentas são trocadas entre aqueles conectados em rede global, que não se submetem a espaços territoriais, tampouco a tratamentos jurídicos diversos, o Brasil busca evitar que tais tecnologias de informação possam se transformar em via convergente ao discurso do ódio, como veremos a seguir.

\footnotetext{
${ }^{12}$ Disponível em <http://www.telesintese.com.br/onu-define-relator-para-direito-privacidade/ . Acesso em 11 jun 2016.
} 
APLICATIVO SECRET: SOMOS TODOS INVISÍVEIS? UM OLHAR CONSTITUCIONAL SOBRE O DIÁLOGO ENTRE ANONIMATO E LIBERDADE DE EXPRESSÃO NO AMBIENTE VIRTUAL

BÁRbara Michele Morais Kunde, Jorge Renato dos Reis

\section{0 anonimato e a (possível) problemática do discurso do ódio sob a ótica virtual}

A máxima da liberdade em uma sociedade democrática é a expressão do pensamento, entretanto, seu exercício (concreto) é limitado pela vedação do anonimato, no sentido de se alcançar, em caso de violação de direitos alheios, o responsável pelos abusos. Vige, portanto, a regra constitucional de que é ampla a liberdade de expressão desde que empregada com responsabilidade.

A vedação ao anonimato objetiva proteger todos os integrantes da sociedade, porque no Estado Democrático de Direito é imprescindível garantir que os direitos sejam observados e os deveres cumpridos, no sentido de que o ofendido tenha a possibilidade de também exercer seus direitos previstos constitucionalmente em caso de violações desta natureza, tais como a reparação de danos, direito de resposta, entre outros.

Além disso, ao mesmo tempo em que a ordem constitucional assegura o direito de manifestar o pensamento, também garante o direito de os demais conhecerem a autoria do pensamento, ou seja, se o indivíduo quer exprimir o que pensa porque por algum motivo entende a informação relevante, àqueles aos quais é dirigida a informação, ainda que sem destinatário determinado no ambiente virtual, é garantida a informação de saber quem foi o emissor da mesma.

Trazendo-se estas observações para o caso concreto da Ação Civil Pública antes referida, se constata que o aludido aplicativo tem grande potencial lesivo se utilizado perversamente, pois seu slogan encoraja a discussão negativa dos fatos ao garantir ao usuário o sigilo absoluto de sua identidade, assegurando que jamais será publicada qualquer informação no Facebook, prometendo, de certa forma, a impunidade.

A respeito da lesividade do anonimato, advertem Gilmar Mendes e Paulo Gustavo Gonet Branco que:

Proíbe-se o anonimato. Com efeito, esta é a forma mais torpe e vil de emitir-se o pensamento. A pessoa que o exprime não o assume. Isto revela terrível vício moral consistente na falta de coragem. Mas, este fenômeno é ainda mais grave. Estimula as opiniões fúteis, as meras assacadilhas, sem que o colhido por estas maldades tenha possibilidade de insurgir-se contra o seu autor, inclusive demonstrando a baixeza moral e a falta de autoridade de quem emitiu estes 
APLICATIVO SECRET: SOMOS TODOS INVISÍVEIS? UM OLHAR CONSTITUCIONAL SOBRE O DIÁLOGO ENTRE ANONIMATO E LIBERDADE DE EXPRESSÃO NO AMBIENTE VIRTUAL

BÁRbara Michele MORAIS Kunde, JORGE RENATO dOS REIS

atos. Foi feliz, portanto, o texto constitucional ao coibir a expressão do pensamento anônimo ${ }^{13}$.

A liberdade de expressão não pode servir de escudo àquele que acusa sem dar o direito de defesa, que critica o caráter ou conduta de alguém sem assumir que assim pensa. 0 anonimato impede totalmente o visado de refutar as informações e fazer o seu contraponto. Significa, pois, submeter o público a apenas uma verdade, e por isso não é aceito pela ordem constitucional, pois descumpriria requisito básico que é o direito de defesa.

Essa perspectiva, trazida para a realidade do ambiente virtual, demonstra que o processo comunicativo é via de mão dupla: recebimento de opiniões alheias e soma às percepções pessoais conforme a opção feita.

Esta nova comunicação, no entendimento de Pierre Lévy ${ }^{14}$, é massiva e interativa, demonstrando muito claramente as etapas através das quais este processo de evolução avança: “[...] ao longo dos modelos “UM-TODOS, UM-UM, para TODOS-TODOS”. Esta definição representa claramente o progresso das relações sociais conforme o desenvolvimento do conceito de liberdade e o amadurecimento de seu exercício, dimensionando a amplitude que um comentário pode alcançar instantaneamente, produzindo consequências positivas ou negativas.

O desejo de ser diferente ou a possibilidade de praticar atos cuja responsabilidade dificilmente será imputada, faz com que os meios tecnológicos sejam, preferencialmente, a via eleita para a perpetração de violações a direitos fundamentais ${ }^{15}$.

Nesse passo, verifica-se que a possibilidade de emitir opiniões preconceituosas, racistas ou discriminatórias é bastante ampliada, dado o potencial que todos têm de serem emissores de informações. 0 anonimato estimula a impunidade do ato lesivo, encoraja o seu emissor, que, acobertado pela falta de identificação pessoal, toma o cuidado de garantir que a pessoa visada leia o que se escreveu a seu respeito, sendo tratada como um inimigo.

Assim é que palavras que tenham intenção de insultar, intimidar pessoas em virtude de religião, sexo, beleza, cor, etnia, nacionalidade, beiram o discurso do ódio, pois têm a finalidade de instigar violência, ódio ou discriminação contra grupos considerados vulneráveis.

\footnotetext{
${ }^{13}$ MENDES, Gilmar Ferreira; COELHO, Inocêncio Mátires; BRANCO, Paulo Gustavo Gonet. Curso de direito constitucional. São Paulo: Saraiva, 2007, p. 43-44.

${ }_{14}$ LÉVY, Pierre. A inteligência coletiva. São Paulo: Edições Loyola, 1998, p. 212, grifo do autor.

15 PEZZELLA, Maria Cristina Cereser; CAMARGO, Ricardo Antônio Lucas. Sociedade da Informação e as redes sociais. In: Juris - Revista da Faculdade de Direito, v. 14, 2009, p.92.
} 
APLICATIVO SECRET: SOMOS TODOS INVISÍVEIS? UM OLHAR CONSTITUCIONAL SOBRE O DIÁLOGO ENTRE ANONIMATO E LIBERDADE DE EXPRESSÃO NO AMBIENTE VIRTUAL

Bárbara Michele Morais Kunde, JoRge Renato dos ReIS

Diante desta realidade é que se analisa o grande impacto que a sociedade em rede causa, merecendo um olhar mais percuciente de vários países, dada a interação em nível global que afeta e altera o modo do ser humano em sociedade, propiciando atitudes mais críticas ou de conformismo, refletindo uma uniformização dos padrões culturais enquanto interesses convergentes.

Não se pode deixar de mencionar que muito embora o contexto promissor, o fenômeno tecnológico na Europa ensejou, inclusive, o renascimento de grupos neonazistas, aumento de atentados terroristas e uma crescente violência em prol do separatismo ${ }^{16}$.

A medida que os novos instrumentos tecnológicos foram assimilados, tornaram-se um modo de pensar, comunicar e agir cotidianamente, e seu conteúdo passou a ser fundamental na qualidade das relações sociais ${ }^{17}$. Desse modo, quando interesses escusos, discriminatórios ou ilegais encontram um mesmo canal de comunicação, pode surgir, então, o discurso do ódio, maquiado pela liberdade de expressar a própria opinião.

Em nosso ordenamento jurídico a realidade que se apresenta é a de que, em que pese não haja um enfrentamento profundo pela Doutrina brasileira envolvendo o tema, o que possibilitaria a formação de um conceito, o entendimento majoritário é de que o discurso do ódio é a manifestação do pensamento que incita à violência, seja física ou psicológica, contra grupos ou pessoas em situação de vulnerabilidade ${ }^{18}$.

Não se pode, pois, considerar que as manifestações de pensamento que tenham estas características são uma faceta da liberdade de expressão, pois o pluralismo próprio dos regimes democráticos assegura o acesso livre às ideias, sempre acompanhado pela responsabilidade moral do indivíduo com respaldo na tolerância, uma vez que ao mesmo tempo em que há o direito de se expressar, há o dever de permitir que a expressão alheia também ocorra.

Deve-se mencionar, ainda, que as ferramentas tecnológicas vão ao encontro dos anseios dos usuários, de modo que "a sociedade é que dá forma à tecnologia de acordo com as

\footnotetext{
16 WACHOWICZ, Marcos, CHRISTAMANN, Luíza Landerdahl. Diversidade cultural na sociedade informacional: promessas e desafios: por uma visão dialética do tema. In: Inclusão tecnológica e Direito à cultura: movimentos rumo à sociedade democrática do conhecimento, Florianópolis: Fundação Boiteux, 2012, p. 322.

${ }_{18}^{17}$ Idem, p. 321.

18 CARCARÁ, Thiago Anastácio. Discurso do ódio no Brasil: elementos do ódio na sociedade e sua compreensão jurídica. Rio de Janeiro: Lumen Juris, 2014, p. 56.
} 
APLICATIVO SECRET: SOMOS TODOS INVISÍVEIS? UM OLHAR CONSTITUCIONAL SOBRE O DIÁLOGO ENTRE ANONIMATO E LIBERDADE DE EXPRESSÃO NO AMBIENTE VIRTUAL

Bárbara Michele Morais Kunde, JoRge Renato dos ReIS

necessidades, valores e interesses das pessoas que utilizam as tecnologias”19. Portanto, a utilização será moldada conforme o perfil do usuário, podendo pender tanto para o lado positivo, quanto negativo, vai depender, em essência, do seu estado interior.

Nesse sentido, Thiago Carcará $^{20}$ ressalta que encontramos uma dubiedade na caracterização do discurso do ódio, dependendo da maneira e da intenção com que o pensamento é externado a ponto de incitar a violência. Significa dizer que o discurso do ódio estará configurado quando não possibilitar o diálogo, pois se baseia na intolerância e no desejo de fazer preponderar a sua opinião em face das demais, não admitindo contraponto, elegendo uma única crença como verdade irrefutável.

A respeito do tema, relevante destacar Daniel Sarmento quanto às consequências produzidas na esfera individual e coletiva:

\begin{abstract}
Mas este ambiente é simplesmente inviabilizado pelo hate speech, que está muito mais próximo de um ataque do que de uma participação num debate de opiniões. Diante de uma manifestação de ódio, há dois comportamentos prováveis da vítima: revidar com a mesma violência, ou retirar-se da discussão, amedrontada e humilhada. Nenhum deles contribui minimamente para a 'busca da verdade, 21 .
\end{abstract}

Como ferramenta comunicativa, o aplicativo Secret permite que os pensamentos ganhem palco e rendam aplausos por parte de muitos destes que compartilham a ideia de intolerância, pois sobre um comentário podem ser feitos outros tantos, igualmente anônimos, intensificando a violência pela identidade de pensamentos. Uns apoiam-se nos outros para alcançar o objetivo comum: ofender, humilhar, duelar (no caso de o ofendido também revidar).

Por esse motivo, há uma probabilidade muito grande de a intolerância e o discurso do ódio preponderarem no exercício da liberdade de expressão se o caminho é utilizado para macular a imagem de outras pessoas, o que se acentua ainda mais em face do anonimato.

\footnotetext{
${ }^{19}$ CASTELLS, Manuel. A sociedade em rede: do conhecimento à política. A sociedade em rede: do conhecimento à acção política. ; CARDOSO, Gustavo (Org.). Belém: Imprensa Nacional - Casa da Moeda, 2005, p. 17.

${ }^{20}$ Ibid., p. 56.

21 SARMENTO, Daniel. Direitos fundamentais e relações privadas. 2. ed. Rio de Janeiro: Lúmen Júris, 2006, p. 236.
} 
APLICATIVO SECRET: SOMOS TODOS INVISÍVEIS? UM OLHAR CONSTITUCIONAL SOBRE O DIÁLOGO ENTRE ANONIMATO E LIBERDADE DE EXPRESSÃO NO AMBIENTE VIRTUAL

BÁRbara Michele MORAIs Kunde, JoRge RenATO dos ReIS

A liberdade de expressão pressupõe tornar públicas as razões das pessoas, independentemente da aceitação ou não, sobre o que muito bem discorre Ronald Dworkin ${ }^{22}$ “[...] sendo esta expressão movida pelo respeito para com as outras pessoas e pelo desejo ardente de que a verdade seja conhecida, a justiça seja feita e o bem triunfe".

Embora a interação global seja o marco característico do ambiente virtual, não se pode admitir que o entendimento alienígena acerca do tema prevaleça sobre a proteção constitucional dispensada à privacidade em território nacional.

O caminho da sociedade brasileira, pois, deve ser o do diálogo, ainda que baseado em argumentos antagônicos, pois a tolerância é premissa da qual devemos todos partir para a concreção da participação política no processo democrático.

\section{Em busca de um equilíbrio: a tutela constitucional da liberdade de expressão e o ambiente virtual}

A sociedade tecnológica, em uma de suas facetas, propiciou uma verdadeira revolução, criando novos meios de comunicação, agora com abrangência global e repercussão instantânea.

$\mathrm{Na}$ ponta dos dedos está a comunicação humana, literalmente. Não há mais espaço impossível de ser ocupado, nem tempo que não possa ser suprido; não há mais limites nem tempo cronológico, basta um clique para estarmos em locais que nunca teríamos acesso não fosse $o$ ambiente virtual.

0 aperfeiçoamento vertiginoso das novas tecnologias exige o enfrentamento de questões igualmente abrangentes, são os novos problemas culturais, legais, éticos de liberdade de expressão e de privacidade de dados pessoais. As ferramentas de manipulação destes novos conhecimentos são instrumentos de poder a influenciar os diferentes grupos sociais que compartilham objetivos e valores, responsáveis pela coesão de seus membros.

A complexidade é tamanha que, diferentemente dos meios convencionais de comunicação, como a televisão e o rádio, por exemplo, que se subordinam a regras das concessões públicas, os computadores, smartphones, iPads, são ferramentas de uso particular e individual, cujo uso foge ao controle de utilização e conteúdo, inclusive do próprio usuário.

22 DWORKIN, Ronald. 0 direito da liberdade: a leitura moral da Constituição norte-americana. Trad. Marcelo Brandão Cipolla. São Paulo: Martins Fontes, 2006, p. 320. 
APLICATIVO SECRET: SOMOS TODOS INVISÍVEIS? UM OLHAR CONSTITUCIONAL SOBRE O DIÁLOGO ENTRE ANONIMATO E LIBERDADE DE EXPRESSÃO NO AMBIENTE VIRTUAL

Bárbara Michele Morais Kunde, JoRge Renato dos ReIS

Nesse contexto, o interesse privado é de suma importância, e por isso as ferramentas se desenvolvem em velocidade galopante para acompanhar o avanço tecnológico. Representam constantes desafios aos seus idealizadores, pois os programas e aplicativos devem manter o interesse dos usuários, o que os leva a criar meios alternativos e inovadores que proporcionem diferentes experiências.

A interação social é responsável pela identidade de uma sociedade, o tempo todo os indivíduos influenciam e são influenciados. Maria Cristina Cereser Pezzella ${ }^{23}$ conclui neste sentido ao afirmar que "o ser humano é um ser sugestionável e o seu grau de vulnerabilidade à sugestão está vinculado à sua educação e ao sentimento interior de paz que pode ser por ele construído", o que importa dizer que a realização da personalidade se dá pela convivência em sociedade que, através da comunicação constante, gera consequências decisivas no modo de se portar.

E a referida autora ${ }^{24}$ conclui ainda que “[...] o ser é mais permeável e sugestionável quanto menor for a sua educação e o sentimento de paz interior que ele experimenta”, ou seja, quanto menos informações o indivíduo tiver, ou dependendo da natureza destas informações, ele será mais sugestionável.

As informações estão todas à disposição de quem interesse obtê-las, no entanto, a transformação cultural somente ocorre quando a sociedade faz uso delas, de modo que a historicidade está intimamente ligada à trajetória de vida, naturalmente descrita nas redes sociais, por exemplo. Cada vez mais dependentes do meio virtual, na visão de Manuel Castells ${ }^{25}$ “estamos alienados pela tecnologia”, acreditando que tudo que está na rede é verdadeiro.

A força normativa da Constituição faz com que os atos civis sejam "filtrados" por seus postulados, exigindo, em primeiro lugar, a promoção da dignidade da pessoa humana.

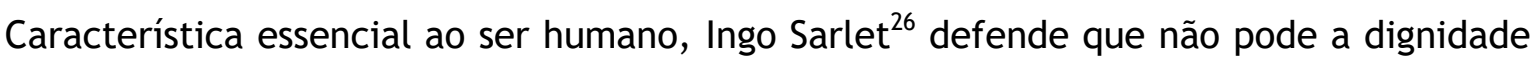
ser uma fórmula esvaziada por mera retórica, destacando ser princípio e norma embasadora de direitos fundamentais, definindo-a como parâmetro para se destinar respeito ao próximo, tanto por parte do Estado, quanto dos particulares de modo a "garantir as condições essenciais mínimas para uma vida saudável". Além disso, promove um sentimento de solidariedade na

\footnotetext{
${ }^{23}$ Ibid., p. 86.

24 Ibid., p. 86.

25 Ibid., p. 19.

26 . Dignidade da Pessoa Humana e Direitos Fundamentais na Constituição Federal de 1988. Porto Alegre: Livraria do Advogado, 2011, p. 73.
} 
APLICATIVO SECRET: SOMOS TODOS INVISÍVEIS? UM OLHAR CONSTITUCIONAL SOBRE O DIÁLOGO ENTRE ANONIMATO E LIBERDADE DE EXPRESSÃO NO AMBIENTE VIRTUAL

Bárbara Michele Morais Kunde, JoRge Renato dos ReIS

sociedade, pois permite "a participação ativa e corresponsável nos destinos da própria existência e da vida em comunhão com os demais seres humanos, mediante o devido respeito aos demais seres que integram a rede da vida" ${ }^{27}$.

Logo, ao se impedir a divulgação do aplicativo, não se está a considerar preponderante a liberdade de expressão em face da privacidade, o olhar deve ser mais percuciente, pois se trata da falta de amparo legal ao anonimato, e por contrariar a Constituição Federal não encontra proteção jurídica, ao contrário, viola diversos outros direitos fundamentais. Vinculada a estas violações, temos, ainda, reflexamente, a violação do direito fundamental de acesso à Justiça, previsto no inciso XXXV do artigo quinto, pois a impossibilidade de imputação da autoria da lesão impedirá a vítima de buscar ressarcimento, que também é um direito fundamental ${ }^{28}$.

Feitas estas considerações, verificamos que o olhar constitucional sobre o anonimato é no sentido de preservar a liberdade de expressão, que é livre e aberta, e também com sua carga de responsabilidade, a resguardar, sempre, outros direitos fundamentais, no sentido de permitir a auto-realização do indivíduo através da eleição de seus valores.

Seguindo as premissas constitucionais, questiona-se até que ponto a liberdade de expressão é livre, com o perdão da redundância. Se há um comentário lançado no mundo virtual a respeito de uma determinada ideia de forma anônima, esta circunstância não propicia um diálogo, pois como dialogar com alguém que não tem coragem sequer de sustentar a própria opinião identificando-se? O anonimato comprova o desejo de impunidade quanto às consequências dos atos civis praticados, impossibilitando a dilapidação das arestas das opiniões divergentes e impedindo a formação de um consenso (relativo) sobre determinado assunto.

Aproximando estes ensinamentos do caso concreto em análise, o olhar constitucional dado à liberdade de expressão deve ser suficiente a determinar a sua essência: a livre formação da personalidade para o alcance de uma vida digna, conforme os valores que o indivíduo eleger, e isso pressupõe, necessariamente, a tolerância para com as desigualdades e divergências, oportunizando que outros também vivam suas verdades sem imposição de ordem.

\footnotetext{
27 Ibid., p. 73.

28 Ibid., p. 44.
} 


\section{CONCLUSÃO}

As novas tecnologias se incorporaram no dia a dia de tal modo que é muito difícil conceber o mundo sem a internet, os computadores ou smartphones.

A sociedade deixou de ser industrial para ser informacional: superada a produção em larga escala, a contemporaneidade trouxe como bem maior a informação. Todavia, não se pode fechar os olhos quanto aos riscos assumidos e reconhecer a iminente possibilidade de violação de direitos fundamentais. O cuidado neste sentido é capital para se encontrar soluções e mecanismos de proteção, notadamente porque a celeridade com que imagens e notícias são difundidas em nível global representa um desafio de complexa superação.

Por outro lado, o progresso exige que o Direito sistematize as modificações sociais para dar segurança e estabilidade ao Estado, conforme seus valores mais caros.

Diante desta realidade é que se analisa o grande impacto que a sociedade em rede causa, merecendo um olhar mais atento de vários países, dada a interação em nível mundial que afeta e altera o modo do ser humano em sociedade.

Preocupada com a proteção aos direitos humanos, notadamente o direito à privacidade no mundo virtual, é que a Organização das Nações Unidas está elaborando um parecer descritivo dos abusos, bem como apontando meios de fomentar a sua concretização, visando unificar o olhar internacional acerca de tema tão relevante. Enquanto isso, os países seguem protegendo o direito à privacidade e o direito à liberdade de expressão a seu modo.

A sociedade brasileira, por sua vez, considerando-se o período pós-Constituição de 1988, é baseada na consagração do pluralismo de ideias, sustentada pela tolerância, condição imprescindível à convivência harmônica. Por isso, a liberdade de expressar pensamentos não compreende somente as informações inofensivas ou favoráveis a uma situação predominante, vai além: contempla também aquelas que ensejam resistência, transtorno, que podem inquietar as pessoas, pois trazem outra perspectiva e fomentam a modificação de opiniões, contribuindo para o progresso da sociedade.

A natureza humana é social por essência, o desenvolvimento da personalidade e a higidez psicossocial se formam do contato com o semelhante. Todas estas relações são geridas 
APLICATIVO SECRET: SOMOS TODOS INVISÍVEIS? UM OLHAR CONSTITUCIONAL SOBRE O DIÁLOGO ENTRE ANONIMATO E LIBERDADE DE EXPRESSÃO NO AMBIENTE VIRTUAL

Bárbara Michele Morais Kunde, JoRge Renato dos ReIS

pela Constituição Federal que reconhece diversos direitos fundamentais que, pela própria denominação, comprovam a sua relevância neste processo de amadurecimento.

Nesse contexto, o interesse privado é de suma importância, e por isso as ferramentas se desenvolvem em velocidade galopante para acompanhar o avanço tecnológico. Representam constantes desafios aos seus idealizadores, pois os programas e aplicativos devem manter o interesse dos usuários, o que os leva a criar meios alternativos e inovadores que proporcionem diferentes experiências.

Em contrapartida, esta ampla possibilidade de comunicação a ser exercida em qualquer parte do mundo e a qualquer hora do dia, gera questionamentos quanto ao seu conteúdo e suas consequências no mundo virtual, principalmente quando a interação está sob o manto do anonimato, podendo a liberdade de expressão ser desvirtuada a ponto de ser fomentadora do discurso da intolerância ou até mesmo do ódio.

Inegável é o fato de as redes sociais constituírem-se em veículos democráticos de expressão de pensamentos, ideias, teorias, opiniões, sendo um ambiente propício a transformar o indivíduo não somente em consumidor da informação, mas também emissor desta, o que enseja a observância de limites para que a dignidade da pessoa humana seja sempre o sustentáculo das relações sociais.

O âmbito de desenvolvimento da personalidade do indivíduo pressupõe a sua liberdade de eleger suas próprias ideias por meio de suas convicções, ter o direito de possuir um juízo moral acerca das mais variadas questões, bem como não sofrer restrições quanto a isso. Portanto, esta liberdade conferida a cada um na escolha de suas posturas, passa, necessariamente, pelo reconhecimento de que o outro integrante do grupo social também está amparado pela Constituição Federal e tem o direito de eleger as suas próprias, mesmo que divergentes ou até mesmo frontalmente contrárias, pois somente assim se operará o amadurecimento intelectual da sociedade.

Este ambiente que busca evidenciar a democracia mediante a contribuição de cada um no debate não é permitido por este prisma essencialmente individual e intolerante que o discurso do ódio pressupõe.

O anonimato do comentário maldoso fortalece aqueles que não ousavam proclamar expressamente sua intolerância, e a união com os que semelhantemente pensavam, fez formarem-se "legiões" que se fortalecem a cada compartilhamento, expandindo a liberdade de expressão que sustentam, confundindo sua intolerância com autenticidade e liberdade. 
APLICATIVO SECRET: SOMOS TODOS INVISÍVEIS? UM OLHAR CONSTITUCIONAL SOBRE O DIÁLOGO ENTRE ANONIMATO E LIBERDADE DE EXPRESSÃO NO AMBIENTE VIRTUAL

BÁRbara Michele Morais Kunde, JoRge Renato dos ReIS

Nesta linha de raciocínio, o anonimato, na medida em que utilizado para ocultar a titularidade de atos violadores de direitos, não contribui para o desenvolvimento desta sociedade almejada pelo constituinte, ao contrário, é caminho livre para a expressão de ideias que fomentam o discurso do ódio a partir da intolerância quanto à convivência com as desigualdades individuais, ou ainda pior, o desprezo em relação a grupos vulneráveis.

E o confronto físico que outrora se vivenciava, o enfrentamento, passa a ser simbólico: a eliminação do outro se dá mediante o comando de deletar ou bloquear, ou, como instrumento de tortura, posts que ofendem a dignidade das pessoas.

Conclui-se, portanto, que o anonimato, cingido à concepção de plena liberdade, ao estimular a irresponsabilidade pode levar as pessoas a um estado de guerra no ambiente virtual, na medida em que os desejos pessoais maculariam moralmente outra pessoa ou grupo.

Logo, a restrição da liberdade em prol da convivência pacífica é uma premissa a ser evidenciada nas relações sociais virtuais, independentemente das tecnologias postas à disposição de seus usuários, sempre voltada à promoção da dignidade da pessoa humana.

Se, por um lado, a liberdade de expressão permite o livre acesso às ideias para a formação da base moral e crítica do ser humano através da filiação a diferentes correntes, o anonimato, se empregado com intenções escusas, não leva ao desenvolvimento desta consciência de forma responsável, pois impede que o diálogo - mesmo antagônico-m, seja estabelecido, que a identidade seja construída, pois que esta se baseia na interação do dia a dia, de modo a conferir-lhe um significado social a integrar uma realidade estatal.

$O$ aplicativo Secret não é nocivo se retirado este mecanismo de postagem anônima, pois independente do Estado, a liberdade de expressão, de um modo geral, é um direito supremo, e assim é pelo fato de se constituir em direito humano internacional. Não se olvide, também, que a liberdade de expressão é intrínseca a esta comunicação através das novas tecnologias.

Somos todos invisíveis? Assim desejariam aqueles encorajados pelo anonimato das ideias irresponsáveis, intolerantes e até mesmo odientas que sua falta de paz interior proporciona. Este viver intolerante apenas desarmoniza a convivência em sociedade, podendo aportar em um estado de verdadeira guerra. E o embate travado, neste ambiente, é muito mais lesivo porque transcende o mundo físico e ocupa o meio virtual, sem fronteiras e controle de quem quer que seja, exceto os princípios ético-morais que cada ser humano construiu em si. 


\section{REFERÊNCIAS}

BRASIL. Aplicativo Secret permite contar segredos anonimamente e vira hit. Disponível em: http://g1.globo.com/tecnologia/tem-um-aplicativo/noticia/2014/08/aplicativo-secret-permitecontar-segredos-anonimamente-e-vira-hit.html. Acesso em 20 maio 2015.

. APP "Secret", de posts anônimos, chega ao fim, anuncia criador. Disponível em: <http://g1.globo.com/tecnologia/tem-um-aplicativo/noticia/2015/04/app-secret-de-postsanonimos-chega-ao-fim-anuncia-criador.html> Acesso em 15 jun 2015.

. ONU escolhe relator para o direito à privacidade. Disponível em ‘http://www.telesintese.com.br/onu-define-relator-para-direito-privacidade/ ‘. Acesso em 11 jun 2016.

BRASIL. Constituição da República Federativa do Brasil. Brasília, DF: Senado Federal, 1988. Disponível em < http://www.planalto. gov.br/ccivil_03/constituicao/constituicao.htm>. Acesso em: 02 jun. 2015.

- Tribunal de Justiça do Estado do Espírito Santo. Agravo de Instrumento $n^{\circ} 0035186$ 28.2014.8.08.0024, julgado em 06 de novembro de 2014. Desembargador Robson Luiz Albanez (relator). Disponível em:

<http://aplicativos.tjes.jus.br/sistemaspublicos/consulta_12_instancias/descricao_proces.cfm> Acesso em 24 maio 2015.

CARCARÁ, Thiago Anastácio. Discurso do ódio no Brasil: elementos do ódio na sociedade e sua compreensão jurídica. Rio de Janeiro: Lumen Juris, 2014.

CASTELLS, Manuel. A sociedade em rede: do conhecimento à política. A sociedade em rede: do conhecimento à acção política. ; CARDOSO, Gustavo (Org.). Belém: Imprensa Nacional -

Casa da Moeda, 2005.

DWORKIN, Ronald. 0 direito da liberdade: a leitura moral da Constituição norte-americana.

Trad. Marcelo Brandão Cipolla. São Paulo: Martins Fontes, 2006.

FARIAS, Edilsom Pereira. Colisão de direitos - A honra, a intimidade, a vida privada e a imagem versus a liberdade de expressão e informação. 3.ed. rev. e atual. Porto Alegre: Fabris, 2008.

LÉVY, Pierre. A inteligência coletiva. São Paulo: Edições Loyola, 1998.

LIMBERGER, Têmis. 0 direito à intimidade na era da informática: a necessidade de proteção dos dados pessoais. Porto Alegre: Livraria do Advogado, 2007.

MENDES, Gilmar Ferreira; COELHO, Inocêncio Mátires; BRANCO, Paulo Gustavo Gonet. Curso de direito constitucional. São Paulo: Saraiva, 2007. 


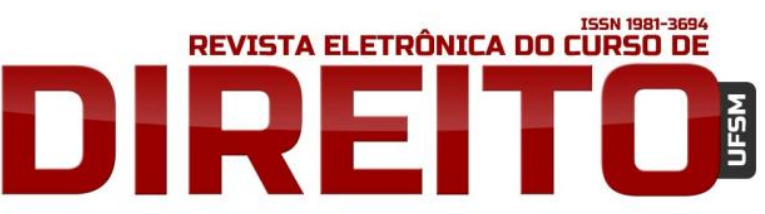

APLICATIVO SECRET: SOMOS TODOS INVISÍVEIS? UM OLHAR CONSTITUCIONAL SOBRE O DIÁLOGO ENTRE ANONIMATO E LIBERDADE DE EXPRESSÃO NO AMBIENTE VIRTUAL

Bárbara Michele Morais Kunde, JoRge Renato dos ReIS

PEZZELLA, Maria Cristina Cereser; CAMARGO, Ricardo Antônio Lucas. Sociedade da Informação e as redes sociais. In: Juris - Revista da Faculdade de Direito, v. 14, 2009, p. 81-103.

SARLET, Ingo Wolfgang.Dignidade da Pessoa Humana e Direitos Fundamentais na Constituição Federal de 1988. Porto Alegre: Livraria do Advogado, 2011.

SARMENTO, Daniel. Direitos fundamentais e relações privadas. 2. ed. Rio de Janeiro: Lúmen Júris, 2006.

. Liberdade de expressão, pluralismo e o papel promocional do Estado. In: Revista Diálogo Jurídico, n. 16 - maio / junho / julho / agosto de 2007, Salvador. Disponível em: <http//www. .grupoddp.com.br/resources/Liberdade\%20de\%20Expressão,\%20Pluralismo\%20e\%20o\%20Papel\%20 Promocional\%20do\%20Estado\%20-\%20Daniel\%20Sarmento.pdf . . Acesso em 10 jun 2016.

SILVA, José Afonso da. Comentário contextual à Constituição. São Paulo: Malheiros, 2005.

SODRÉ, Nelson Werneck. História da imprensa no Brasil. 4 ed. atual. Rio de Janeiro: Mauad, 1999.

WACHOWICZ, Marcos, CHRISTAMANN, Luíza Landerdahl. Diversidade cultural na sociedade informacional: promessas e desafios: por uma visão dialética do tema. In:Inclusão tecnológica e Direito à cultura: movimentos rumo à sociedade democrática do conhecimento, , PRONER,

Carol (Org.). Florianópolis: Fundação Boiteux, 2012, p.309-338.

Recebido em: 18.12.2015 / Revisões requeridas em: 12.05.2016 / Aprovado em: 20.06.2016 